\title{
SUCATA COMO ELEMENTO DE COMUNICAÇÃO NA ENFERMAGEM
}

Elizabeth Esperidião *

Maria Eunice Medeiros Teixeira* Jeanne Marie Rodrigues Stacciarini*

ESPERIDIÃO, E.; TEIXEIRA, M.E.M.; STACCIARINI, J.M.R, Sucata como , elemento de comunicação na enfermagem, Rev.latino-am.enfermagem, Ribeirão Preto, v. 4, $\mathrm{n}^{\circ}$ especial, p, 101-11, abril 1996.

A partir do entendimento de que alunos e profissionais de Enfermagem demonstram dificuldades em se posicionarem como "pessoas" na profissão, realizamos um estudo descritivo exploratório, com abordagem qualitativa, Oferecemos na II Jornada Goiana de Enfermagem uma oficina de trabalho intitulada "Conhecendo o SER Enfermeiro", Dentre II as várias técnicas de grupo, a sucata como elemento de comunicação foi um recurso utilizado em determinada dinâmica, sendo o objeto deste estudo que se propôs: identificar como é a representação do auto-retrato do SER Enfermeiro, verificar qual é o processo de interação indivíduo-sucata, durante a realização do trabalho e averiguar se o objeto de escolha assume uma representação diferente do que ele é, Encontramos que existem especificidades na representação de cada auto-retrato do SER Enfermeiro. Quanto à interação indivíduo-sucata houve uma certa seqiiência obedecida: estranheza com o material e/ou trabalho proposto, manipulação e identificação dos objetos, seleção de sucatas e concretização da tarefa realizada. Em relação aos objetos escolhidos percebemos nítida preferência aos correlacionados com a profissão, embora outros também o foram. Finalizando, sugerimos que outros estudos sejam realizados, utilizando sucata enquanto elemento de comunicação.

UNITERMOS: comunicação, sucata

* Docentes da Faculdade de Enfermagem e Nutrição da Universidade Federal de Goiás

Rev. Latino-am.enfermagem - Ribeirão Preto - v. 4 - n. especial - p. 101-111 - abril 1996101 


\section{APRESENTAÇÃO}

O convívio no meio acadêmico, enquanto docentes, nos favorece a percepção de que geralmente os alunos e também os profissionais da Enfermagem demonstram dificuldades em se posicionarem como "pessoas", uma vez que a solicitação "maior" é a de atuarem como "profissionais".

A idéia de que o autoconhecimento é imprescindível para facilitar o processo de relacionamento interpessoal, vem geralmente acompanhada de inúmeras restrições.

São vários os impedimentos (pessoais e profissionais) que podem influenciar os aspectos intrapessoais que permeiam as ações de Enfermagem, quer seja em níveis interpessoais ou grupais.

Os enfermeiros parecem incapacitados para admitir a necessidade de troca, de um compartilhar com o paciente, distanciando das emoções que envolvem o relacionamento enfermeiro-paciente.

Defensoras de uma abordagem Humanística na Enfermagem identificamos que na prática, ainda existe uma dicotomia entre nosso "lado de fora" (profissional) com o nosso "lado de dentro" (aspectos intrapessoais).

SILVA (1991) nos relembra que o ser humano é realmente indivisível (corpo, mente, afeto e espírito) e com isso seus afetos e pensamentos, se expressam no nível físico.

Nesta postura que a Enfermagem freqüentemente vêm assumindo, observamos que o modo de comunicação presente é a dupla mensagem; "a forma verbal da mensagem dá uma informação contrária ao que é demonstrado na forma não-verbal" (Bateson apud STEFANELLI, 1990).

Aprendemos e tentamos executar com perfeição que na assistência de Enfermagem o lado pessoal deve ficar recolhido interiormente, ou seja, não deve ser expressado.

A partir do entendimento de que o SER Enfermeiro não está dissociado em nenhum momento do SER Humano (pessoa que é), oferecemos na II Jornada Goiana de Enfermagem, uma oficina de trabalho intitulada "CONHECENDO O SER ENFERMEIRO".

Estimular o auto-conhecimento, exercitar a auto-percepção e favorecer a valorização da pessoa humana (SER) do profissional de Enfermagem, eram idéias centrais do trabalho executado; para tal recorremos a várias técnicas de grupo, facilitando o desenvolvimento da vivência.

A utilização da sucata como elemento de comunicação, em determinada dinâmica da oficina, foi o objeto deste estudo, que teve os seguintes objetivos:

- identificar como é a representação do auto-retrato do SER Enfermeiro;

- verificar qual é o processo de interação indivíduo-sucata, durante a realização do trabalho; 
- averiguar se o objeto (sucata) de escolha assume uma representação diferente do que ele é.

\section{REVISÃO DA LITERATURA}

Desde que nascemos, um mundo de signos nos cerca e suas inúmeras possibilidades comunicativas passam a fazer parte de nossa realidade tornando-nos capazes de elaborar nossas mensagens através da associação e da imitação.

As palavras, como signos, são o revestimento dec nossas idéias na comunicação verbal sendo que na não verbal difundimos nossos sentimentos livres de interferências.

Conceptualmente, "a comunicação humana corresponde miríades de formas, através das quais os homens transmitem e recebem idéias, impressões e imagens de toda ordem. Alguns desses símbolos, embora compreensíveis jamais conseguem expressar-se por palavras" (PENTEADO, 1986).

O mesmo autor refere que a comunicação humana é assim resposta a um estímulo interno, ou externo. Esta resposta forma na mente uma idéia ou uma imagem com o seu símbolo representativo, que conhecemos por experiência anterior: o nome. É o sentimento resultante dessa experiência que expresso, completa o processo da Comunicação humana.

GUARESCHI (1991) cita McLuhan quando afirma: "O que se percebe, então, é que o tio de comunicação, tem a ver com a configuração do ser humano". Não é difícil mostrar como nós somos em grande parte o conjunto de relações que tivemos estabelecido. O ser humano se forma historicamente e se estrutura a partir das relações que vai criando. E a comunicação é certamente, umas das relações mais persuasivas e abrangentes que pode ajudar a construção de um ser humano autônomo, equilibrado, democrático, cooperador ou, de outra parte num ser humano dependente, submisso, massificado, robotizado".

VIEIRA (1978), refere-se à comunicação não verbal como transmissão de mensagens sem o uso de palavras; afirma que numa interação, os indivíduos se comunicam não verbalmente por meio de gestos, expressões faciais e movimentos corporais.

Concordamos em parte com a autora, todavia acrescentamos que os objetos em geral também possuem significativa importância. Estes são usados para percepção de sentimentos, emoções e impressões.

HERAS (1974) enfatiza que os códigos ou sistemas utilizados pelo homem para desenvolver sua função vital de significar, isto é, de projetar suas vivências por meio de signos são fundamentalmente as palavras e os gestos. Não desconsiderando este posicionamento, pensamos que os objetos podem ser acrescentados a estes signos.

Rev. Latino-am.enfermagem - Ribeirão Preto - v. 4 - n. especial - p. 101-111 - abril 1996103 
STEFANELLI (1993) ressalta que temos de estar atentas a percepção da comunicação não verbal. Nem sempre a mensagem não verbal tem o mesmo significado para diferentes pessoas e situações, O que exige validação verbal da compreensão dos sinais não verbais percebidos. Cada ser humano tem um universo próprio.

TEIXEIRA (1991) confirma que devemos levar em consideração os aspectos que tendem a revelar os sentimentos reais de uma pessoa, trazendo significados mais profundos do que as próprias expressões verbais. Através da expressão facial, apresentamos uma variedade de emoções que pode transmitir sensações diversas.

Para SANNA (1983) a ocorrência entre a comunicação verbal e não verbal é muito importante e mais difícil de ser usada terapeuticamente, pois em geral não temos controle consciente da mesma.

MORAN (1988) conceitua comunicação "como um complexo de interações em vários níveis (do interpessoal ao social) que viabiliza e expressa vários processos e níveis de troca simbólica de sistemas de significação, de veiculação ideológica dentro do universo cultural". Mostra e expressa relações entre grupos, classes, instituições, interliga o tecido social, a trama das relações humanas dinamizando e dando significado a essas relações.

DUGÁS (1984) referindo-se a comunicação não verbal salienta a linguagem corporal que consiste nas expressões faciais, nos gestos, postura, modo de caminhar. Considera importante que o meio escolhido consiga dar ao receptor o propósito exato da mensagem.

No que se refere ao uso de sucatas, os estudos correlacionados à Enfermagem parecem ainda incipientes.

Em concordância com ROSA et al (1993), achamos relevante a utilização de sucatas como mais um recurso de incentivo aS expressões em geral.

FERREIRA (1975) considera sucata, ferro inutilizado pelo uso ou pela oxidação que uma vez refundido é novamente lançado no comércio. Qualquer obra metálica inutilizada.

Neste estudo, compreendemos sucata como material e/ou objeto de diferentes composições em termos de textura, peso, tamanho, cor e formas, sem utilidade específica que mantinha na sua versão original.

WEIL (1986) enfatiza que "objeto também fala!" Para ele, todo e qualquer objeto relacionado com pessoa adquire uma linguagem própria.

\section{REFERENCIAL TEÓRICO}

Como forma de embasamento sistematizado, utilizado a conceituação introdutória, que se refere às teorias de os signos, apresentada por LITTLEJOHN (1982). 
A descrição de que "essencialmente, toda abordagem teórica da comunicação reconhece como um fato básico que a comunicação se efetua através do uso dos signos", (LITTLEJOHN, 1982), nos remete à reflexão da amplitude do assunto em questão: os signos.

De acordo com o mesmo autor, "a realidade de uma pessoa é representada para o eu e os outros com signos", sendo estes verbais e não verbais.

Embora não exista um conceito universal, nesta visão teórica "signo é um estímulo que se considera representar algo diferente dele mesmo" (LITTLEJOHN, 1982).

É complexo quando pensamos e tentamos entender profundamente está definição, embora em uma primeira análise possa parecer simplista. As diferenças culturais e sociais que nos envolvem podem gerar controvérsias, portanto partimos do princípio que os objetos utilizados na dinâmica eram simples e de conhecimento de todos.

Como forma complementar, achamos pertinente e de valor fundamental o entendimento de codificação.

Segundo LITTLEJOHN (1982) "codificação é o processo de relacionar signos com seus referentes"; para nossa compreensão esta integral idade é o que enriquece ainda mais a importância dos signos.

\section{MÉTODO UTILIZADO}

Optamos por um estudo descritivo exploratório com abordagem qualitativa.

Foi desenvolvido a partir de uma oficina de trabalho intitulada "conhecendo o SER Enfermeiro", por ocasião da II Jornada Goiana de Enfermagem, realizada no período de 13 a 15 de outubro de 1993.

Esta oficina aconteceu na Faculdade de Enfermagem e Nutrição da Universidade Federal de Goiás, mais especificamente em uma sala de dramatização, a qual supomos adequada aos tipos de trabalhos realizados.

Desta forma, limitamos o número de participantes que foi reduzido e composto ao acaso, exclusivamente por acadêmicos de Enfermagem e enfermeiros, sendo todos do sexo feminino. Para fins da pesquisa, estes elementos foram considerados sujeitos.

A coleta de dados ocorreu por meio de observação direta durante uma das técnicas empregadas no decorrer da vivência-técnica de auto-retrato, cujo objetivo principal era despertar cada indivíduo do grupo para a auto-observação, de acordo com a compreensão do seu lado profissional no pessoal. .

Como recurso didático, utilizamos sucatas de natureza diversificada e não somente às correlatas com a prática da profissão (pregos, parafusos, cubos, 
cilindros de papel, bolas de isopor, pires, xícaras, pequenos blocos de granito, caixa de ovos, seringas, equipos, frascos de soro, entre outros).

Uma vez orientado o grupo com relação a técnica propriamente dita, os coordenadores distribuíram no centro da sala os materiais a serem trabalhados, iniciando-se assim, o período de observação.

Esta observação direta constitui-se de registros através de fotografias, previamente autorizadas pelos sujeitos e anotações por parte dos coordenadores, dos conteúdos verbais e não verbais expressos por cada elemento do grupo.

Importante salientar que tal dinâmica foi oferecida aos participantes num momento em que não eram totalmente desconhecidos entre si, situação considerada facilitadora para a livre expressão.

Os dados compreenderam as etapas da montagem do auto-retrato, os objetos utilizados pelos sujeitos e ainda o significado que foi atribuído ao seu "produto" (autoretrato concretizado), através de relato verbal, quando cada elemento teve a oportunidade de destacar seus traços e/ou características mais marcantes de sua personalidade.

A análise dos dados ocorreu com base em conceitos fornecidos por LITTLEJOHN (1982) e nas observações realizadas durante a técnica.

\section{DISCUSSÃO DOS DADOS}

Adotamos a forma descritiva, para o relato dos conteúdos evidenciados, os quais estarão associados às leituras realizadas e as nossas experiências profissionais e pessoais já adquiridas.

Não pretendemos fazer julgamento dos fatos, colocando em níveis de conceitos, embora no ato de descrever possa denotar algum juízo de valor.

Conforme relatamos anteriormente, as sucatas utilizadas eram simples, de natureza conhecida dos sujeitos e de grande variedades.

O processo de interação indivíduo-sucata, parece ter obedecido a uma determinada seqüência, as quais passamos a mencionar.

Inicialmente, quando as sucatas foram pelos coordenadores espalhadas no chão e os objetivos da técnica verbalizadas, nos deparamos com olhares de estranheza, sussurros e verbalizações que indicavam "algo diferente" e "estranho", para os participantes.

Lentamente, a etapa acima descrita, foi dando lugar ao manuseio dos materiais expostos; começaram a manipulá-los e identificá-los; a fase denominamos reconhecimento.

Em seguida, os objetos preferidos foram individualmente selecionados. É 
importante ressaltar que neste momento, o silêncio invadiu o ambiente, possivelmente nos mostrando que havia uma busca interior de como representar seu auto-retrato, partindo para a concretização deste: como etapa subseqüente.

Observamos nítida preferência dos indivíduos em escolher objetos correlacionados com a profissão: vidro de remédio, frasco de soro, seringas, equipos, bandeja e remédios, embora também tenham escolhido outros que não estes.

Nos reportando a LITTLEJOHN (1982), quanto à conceituação de signo, podemos afirmar que o fato de preferirem objetos ligados a área profissional para representá-la, implicou em não utilização de signos, ocorrendo simplesmente uma simbolização, embora isto não tenha ocorrido na totalidade.

A análise dos "produtos" elaborada pelos sujeitos associada aos relatos verbais do grupo que, de acordo com o referencial teórico adotado neste estudo, traduz-se à codificação, permitiu-nos observar uma manifestação mais evidente de "pessoas operantes da profissão" e em menor expressão como "pessoas profissionais".

Verificamos que no objeto de escolha de alguns sujeitos nem sempre havia a interação desejada (pessoa/profissional). Houve aqueles que na codificação se restringiram ao ambiente hospitalar, atendendo-se aos aspectos estritamente profissionais.

Às vezes o objeto escolhido não tinha necessariamente correspondência à profissão, mas foi este o significado que Ihe foi atribuído. Esta situação ocorreu, por exemplo, com embalagem de sabonete, carrinho de brinquedo, bola de isopor, copo, cilindro de papel etc. No entanto, nestes "produtos" também foram utilizados objetos estritamente ligados à assistência de enfermagem, tais como: seringas, frascos de soro, entre outros.

STEFANELLI (1990) afirma que o nível intrapessoal da comunicação humana faz parte dos níveis interpessoal, pequeno grupo e de massa. Percebemos que aparentemente em alguns indivíduos seus aspectos intrapessoais parecem cristalizados no mais profundo de seu interior, impedidos de uma exteriorização.

Evidenciamos também o fato oposto, ou seja, o uso de um objeto que pela sua própria natureza, correlacionar-se-ia à profissão, porém foi expresso como referência pessoal, demonstrando uma riqueza na utilização dos signos.

Esta questão nos remete às formas e técnicas de comunicação salientadas por STEFANELLI (1990) a qual enfatiza a necessidade de utilizar a validação como estratégia para identificar se a comunicação não verbal está em consonância com a mensagem expressada, favorecendo o relacionamento terapêutico.

No caso específico, o sujeito referiu-se à seringa e ao desmembrar suas partes (embolo e corpo) representou seu lado pessoal e profissional, elementos presentes em si, ora funcionando em perfeita harmonia, ora em completa desintegração. Por outro lado, demonstrou consciência que as partes não trabalham em separado, sendo necessário encaixá-las adequadamente para atingir o equilíbrio. 
Enfatizou ainda que o treino e o exercício da profissão contribuiriam para alcançá-lo.

Aspecto semelhante, quanto à utilização de signos, também ocorreu com outros sujeitos que utilizaram objetos não direcionados à profissão para referi-la.

A dissociação pessoa/profissional foi um dado marcante no grupo, embora com representações diferentes. Chamou-nos a atenção uma montagem que continha vários objetos relacionados à Enfermagem e um outro em certo destaque, em movimento, representando a sua pessoa -tratava-se de um pião de plástico que, ao girar aproximava-se e/ou distanciava-se da "profissão", permitindo ou não manifestar-se com maior ou menor intensidade como pessoa. Era evidente a oscilação não muito controlável por ela própria.

De acordo com SILVA (1991) "nossos sentimentos estão expressos nos nossos atos, no nosso corpo, assim como os dos nossos clientes estão expressos nos deles. A maior parte das vezes não falamos sobre eles, mas os demonstramos de forma não verbal". A autora salienta que compreender-nos e compreendê-los torna mais fácil o aprender a "ler" conscientemente o mundo da comunicação não verbal.

Dentre as variações de codificação houve uma que diversificando das demais, distinguiu claramente o papel de mãe/mulher da profissional, porém destacou um vínculo de ligação entre os dois papéis, através de uma fita de tecido ligada às duas extremidades onde estavam representadas a pessoa e a profissional, respectivamente. O relato verbal deste membro do grupo reforçou o mecanismo de retroalimentação existente entre as partes, embora estivessem separadas na representação espacial.

Analisando todos os dados que foram possíveis de serem coletados, podemos afirmar que há uma gama enorme de variedade nas formas de expressão, quer sejam verbais ou não verbais. Observamos ainda que, quando estimulados, tal riqueza pode ser percebida pelos sujeitos, fato demonstrado na criatividade da escolha de determinados objetos, signos chegando à codificação.

\section{CONSIDERAÇÕES FINAIS}

É fundamentalmente necessário relatarmos que o momento vivido com os sujeitos do estudo transcende os relatados aqui expressos.

Mediante os objetivos propostos inicialmente, verificamos que existem especificidades na representação de cada auto-retrato do SER Enfermeiro: alguns conseguem se perceberem mais facilmente, em contra-posição, para outros, parece uma tarefa árdua e complicada.

Ainda com relação ao auto-retrato, evidenciamos que para algumas 
pessoas o lado pessoal encontra-se no lado profissional, na tentativa de fazê-la de forma equilibrada. Para outros, estes aspectos estão separados, embora às vezes se interligam formando um "elo de ligação". Encontramos ainda, aqueles que não conseguem se visualizar enquanto pessoa na profissão; são exclusivamente "profissionais".

Quanto à interação indivíduo-sucata, os sujeitos obedeceram uma seqiiência: estranheza com o material e/ou trabalho proposto, manipulação e identificação dos objetos, seleção de sucatas e concretização da tarefa solicitada. Cada etapa traz aspectos peculiares a cada, um em termos de sensibilização, mas semelhanças em termos de funcionamento no grupo,

No que se refere aos objetos de escolha percebemos nítida preferência aos correlacionados com a profissão, embora também outros tenham sido escolhidos.

Não podemos nos abster de nossos posicionamentos frente a significativa importância e enriquecimento no âmbito da comunicação verbal e não-verbal que a realização deste estudo nos proporcionou, Por considerarmos a sucata um recurso valioso e facilitador do processo de comunicação, sugerimos que fosse mais explorada, não somente durante a formação profissional, mas também em situações decorrentes de sua prática.

\title{
"SCRAP" AS AN ELEMENT OF COMMUNICATION IN NURSING
}

\begin{abstract}
Based on the understanding that students and nursing professionals demonstrate difficulties in being a "person" in the profession, we developed a descriptive and exploratory study with a qualitative approach. Then, we offered during the "lind" II Nursing Congress in the city of Goiânia a work-shop called "LEARNING ABOUT NURSE'S ENTITY". Among various processes of work-groups: the "Scrap" was used as a kind of communication. It was a resource utilized in certain dynamics, being the object of our study that has the following goals: to identify the representation of nurse's "entity" to verify the interaction process "man-scrap" during the realization of the work and to verify if the object is represented as it really, is. We have seen that there are particularities in the representation of nurse's entity. Regarding "man-scrap" interaction it had the followed sequence: finding strange the material and the proposal of work, manipulating and identifying objects, "scrap" selection and concretion of the job. With respect to the objects, we perceived a clear preference to the ones related to the profession. Finally, we suggest that other studies about the "scrap" communication element, must be developed.
\end{abstract}

UNITERMS: communication, "scrap"

Rev. Latino-am.enfermagem - Ribeirão Preto - v. 4 - n. especial - p. 101-111 - abril 1996109 


\section{"DESPERDICIOS" COMO ELEMENTO DE COMUNICACIÓN EN LA ENFERMERÍA}

A partir del entendimiento que los alumnos y profesionales de enfermería demuestran dificultades en posicionarse como personas en la profesión, realizamos un estudio descriptivo exploratorio, con abordaje cualitativa, ofreciendo en la II Jornada de Enfermería en Goiania un taller de trabajo titulado "Conociendo el SER Enfermero". Entre varias técnicas de grupo, el "desperdicio" como elemento de comunicación fue un recurso utilizado en determinada dinámica, siendo el objeto de este estudio que se propuso: identificar cómo es la representación del auto retrato del SER Enfermero, verificar cual es el proceso de interacción individuo - "desperdicios", durante la realización del trabajo y averiguar si el objeto escogido asume una representación diferente de los que es. Encontramos que existen especificidades en la representación de cada auto retrato del Ser enfermero. En cuanto a la interacción individuo "desperdicios" huvo una cierta secuencia de los objetos, selección de "desperdicios" y concretización de la tarea realizada en relación a los objetos escogidos percibimos nítida preferencia a los relacionados con la profesión, aunque otros también lo fueran. Finalizando, sugerimos que otros estudios utilizando "desperdicios" como elemento de comunicación sean realizados.

UNITERMOS: comunicación, “desperdicio"

\section{REFERÊNCIAS BIBLIOGRÁFICAS}

01. DUGÁS, B.W. Capacidade de comunicação. In: Enfermagem prática. 4. ed. Rio de Janeiro: Koogan, 1984. cap. 8, p. 99.

02. FERREIRA, A.B.H. Novo dicionário da língua portuguesa. Rio de Janeiro: Nova Fronteira, 1975. p. 1333.

03. GUARESCHI, P.A. A realidade da comunicação: visão geral do fenômeno. In: Comunicação \& Controle Social. Petrópolis: Vozes, 1991. p.20.

04. LITTLEJOHN, S.W. Fundamentos teóricos da comunicação humana. Trad. Álvaro Cabral. Rio de Janeiro: Zahar, 1982. p. 407.

05. MORAN, J.M. Elementos para pensar a comunicação. In: CONFERÊNCIA SIBRACEN. Anais. Ribeirão Preto, 1988. p. 66-94.

06. PENTEADO, J.R.W. Conceitos de comunicação humana. In: A TÉCNICA DA COMUNICAÇÃo HUMANA. 10 ed. São Paulo: Pioneira, 1986. cap. 1, p. 1.

07. SANNA, M.C. A comunicação em enfermagem pediátrica. Rev.Paul.Enfermagem, v. 3, n. 3, p. 103. maio/jun., 1983. 
08. SILVA, M.J.P. da. Percebendo os sentimentos de maneira não-verbal. Rev.Paul.Enfermagem, v. 10, n. 3, p. 128-32, set./dez., 1991.

09. STEFANELLI, M.C. Ensino de técnica de comunicação terapêutica enfermeirapaciente. São Paulo, 1985. p. 163. Tese (Doutorado) - Escola de Enfermagem, Universidade de São Paulo.

10.

Comunicação com o paciente, teoria e ensino. 2 ed. São Paulo: Robe Editorial, 1993, p. 36-7.

11. TEIXEIRA, M.E.M. Relação terapêutica entre a equipe de enfermagem e o paciente submetido a cirurgia de pequeno, médio e grande portes. Rio de Janeiro: UFRJ, 1991. p.80. Dissertação (Mestrado) - Escola de Enfermagem Anna Nery, Universidade Federal do Rio de Janeiro.

12. VIEIRA, T.T. O processo de comunicação na enfermagem. Salvador: Universidade Federal da Bahia, 1978. p. 23.

13. XIFRAS-HERAS, J. A informação análise da liberdade frustrada. Trad. Gastão Jacinto Gomes. Rio de Janeiro: Lux, 1974. p.8-10.

14. WEIL, P. O corpo fala: a linguagem silenciosa da comunicação não verbal. Petrópolis: Vozes, 1986. p. 164. 